\title{
City English Pragmatic Analysis in the New Media Perspective
}

$$
\text { Yang Wang }{ }^{1, \text { a }}
$$

${ }^{1}$ Foreign Language College, Jilin Agricultural University, Jilin, Changchun, China, 130000
\[ { }^{a} \text { email, } \]

Keywords: City, English Pragmatic Analysis, New Media

\begin{abstract}
Pragmatics is one of the areas of contemporary linguistics with rapid development. It examines the meaning of discourse in communication and how the speaker / author passed and how readers are understood. With the rapid development of computer technology, computers, mobile phones and other new media have impact and influence on the lives of urban, making the city more closely linked with the international. English is also penetrated into all aspects of urban life, such as urban public signs, urban public transportation tools. This paper will combine English pragmatics theories analyzed the urban English language phenomena in the perspective of new media.
\end{abstract}

\section{Introduction}

Pragmatics is a relatively new field of linguistics. The term was first raised in 1938 by the philosopher Charles Morris in his "Symbol Theoretical Basis". But after 40 years, the scope of pragmatics research is only confined to the philosophical category until 1977, "Journal of Pragmatics" is founded, the pragmatics was born as an independent discipline. 1983 the first pragmatics textbook of S.C Levinson "Pragmatic" was published in 1986. It marks the establishment of Pragmatics and it has become a specialized and mature discipline. Although domestic language study was late, in just a decade or two, pragmatics has rapidly become the important research in foreign language academia.

With the deepening of China's reform and opening up, English has been used widely in China in newspapers, radio, television networks, presentation, city streets and other public places. Store logo with English translation is also increasing. The use of English is in the convenience of foreigners living in China, while also providing opportunities and culture atmosphere to learn English for the Chinese people, improve the city's image. But while the English is widely used in Chinese cities, there have been some problems, this paper attempts to analyze and explore the use of non-standard English in the city in new media perspective from English pragmatic perspective and promote suggest improvements in order to promote the harmonious development of the city.

\section{The Meaning of Pragmatics}

Pragmatics should be studied in two senses, that meaning conveyed by speaker and that meaning the reader to understand, that generate and understanding of discourse. Research on speaker's meaning is inseparable from the context. In a given context condition, the speaker hoped what kind of information or intent in the context and what is being said (that is, the literal meaning of the words themselves expressed by words). Thus, the speaker tends to organize and build their own content or information hope to be expressed according to the interviewee, time, location and other objective conditions. Therefore, we further believe that "pragmatics study the contextual meaning."

On the other hand, in order to know the speaker what information wanted to convey in communication, obedient people often need to reason the content unspoken, so to study how obedient people to reason for information the words didn't express at face and that means the implicit discourse significance. So, pragmatics can be defined as "the study of how to deliver more content information through discourse confessed" that is, pragmatics speaker is how to pass additional information through the literal meaning of words or between the lines. 


\section{The Basic Theory and Principle of Pragmatics}

Speech Act Theory. According to British scholar Austin views, the language is not just for narrative, more importantly, it is used to "as applied", that is to say certain words, once it is an act. For example, in the discourse of "promise" , 'apology "," thank you "," accused "," approval "," congratulations ", it is not an" expression". Austin put the behavior words into words act, illocutionary act, for example, in his study, where the owner is receiving guests, during the conversation the guest takes a pack of cigarette from his pocket to invite the owner to smoke, the owner said: "I have some allergies to smoke taste." This sentence is a statement in itself within the behavior. And the owner said this is undesirable guests to smoke in front of him, which is illocutionary acts. Guests take the cigarette back into the pocket and do not smoke after listening to the words of the owner.

Indirect Speech Act Theory. Based on the theory of the speech acts of Austin, Searle first proposed the indirect speech act theory in 1969, and it is defined as: to implement another speech acts indirectly through a speech act. (1975, quoted from what nature, 1997: 94) For example, a person ask others to do things for themselves, they more often did not send instructions directly, but by talking to the specific circumstances and then use different means of expression to achieve their purpose. "Can you speak a bit louder" is a form of questions, but in the classroom it's function is to "request." Listeners do not think people saying this is in doubt his "capacity", in that context, he appreciated the indirect meaning of the phrase, the "illocutionary act" in the hope that he "answered a little louder." In indirect speech act, the speaker and listener communicate and the listener can understand the intention of discourse beyond the literal sense, what he relied on is he known enough background information or context with the his hearer, including the non-verbal language. At the same time, we must rely on the listener's ability to reason.

Cooperative Principle and Conversational Implication. The main principles of Session Grice of cooperation are: 1) the amount of chat conversation, both parties should provide the required information, neither more nor less; 2) quality: tell the truth, do not tell lies, do not say words not according to the reality; 3) associated with: the content of speech should be related to the topic; 4) manner: to speak should understand the meaning, short, succinct, well organized to avoid ambiguity.

Compliance with these guidelines, people can communicate in the most direct way, the most efficient and most reasonable language. But in real life, people in communication often do not follow these guidelines, even deliberately violate these guidelines. Grice believes that when people find each other in communication deliberately violate these guidelines, they accordingly pragmatic inference to derive the implied meaning that go beyond the literal meaning of the words, which is "conversation implication"

Politeness. Grice's pragmatic view has led to interest in academia, which is discussed more is people in verbal exchanges have to abide by the principles of cooperation, then why should deliberately violate this principle? Leech believes that if you want to explain why the speaker in speech communication deliberately violation of the principles of cooperation, so that the listener to sense the speaker's true intentions, and that is because of politeness, so he proposed the principles of politeness in verbal communication to follow. He believes that the principle of cooperation is not perfect, politeness can "rescue" the principles of cooperation, and cooperation principle has complementary benefits, politeness can be used to reasonably explain why people in verbal communication to deliberately violate the principles of cooperation in the guidelines. There are six criteria of Politeness, each criterion there are two secondary criteria: (1) Appropriateness criteria. Reduce the expression of prejudicial views of others. Let others suffer as little as possible; so that benefit others as much as possible. (2) Generous guidelines. Make others benefit as little as possible; make yourself suffer as much as possible. (3) Recognition criteria. Belittle others as little as possible; praise others as much as possible. (4) Guidelines for modesty. Praise them as little as possible; belittle yourself as much as possible. (5) Consistent with the guidelines. To minimize the differences between the parties; maximizing both parties agreed. (6) Sympathy guidelines. Minimize both antipathy and maximize both sympathy. 


\section{The Use of English in Cities}

English is used most frequently in cities is logo. Logo is also called social sign language or public sign language. It is a kind of social management language in the social, public logo has a very wide range and it is special language phenomenon. From the point of view of the scope, as long as the printed or posted in public places, providing services and advocacy, the public language signage (banners) belong to the logo. From the perspective of Speech Act, the logo is the art with valid language information to convince others and it is a special language communication activities. The obvious feature and purpose is the identify language is "one-way communication." The particularity of logo language is because it exists between managers and their managers and they are relatively specific communicative place, at a certain time it not to direct communication with both infiltration and it is not limited to individual people. The communication objects of logo are a place for all audiences. Many logos have their own special role and right to remind the audience, referring to the behavior of the audience demonstrators were forced so you can regulate and manage audiences and this is the purpose of logo communication. Generally function of logo is relatively abundant such as publicity, warnings, tips, and other persuasion.

From the development of the city, there are more or less most typical error in streets logo of many cities and the wrong issues are exists mainly in three aspects. (1) misspellings, capitalization, spelling. In the city logo of English spelling, there are very serious mistakes in capitalization names, place names, Chinese names spelling and other errors. For example, some parts of the female toilet hanging "NVRE-STROOMS " If foreigners want to go to the bathroom because of urgency, you how to get in if you see this sign? As another example, in some places the" customer reception ", the corresponding English wrote "KEHU OFFICE" it seems incomprehensible to foreigners. The English name of Henan Pingdingshan emergency command center is "Pingdingshan Ambulance Center " this English is wrong and it should be" Pingdingshan First Aid Center.(2) the translation of same name is not the same. The English name for the same place should be the same for a logo otherwise there will be trouble and misunderstandings for audience, such as the Yin Ruins in Anyang, "the two different translations of the same name are not match and the foreign tourists are more difficult to understand .(3) grammar translation is incorrect. City public logo English translation is often a syntax error. The name some city streets, such as Chang'an Avenue, translated into "CHANG AN JIE", the "people of East" is translated into "RENMINDONGLU" this Pinyin Translation is incorrect, it should take generic parts of the translation or literal approach such as ", JIE " DONGLU " to facilitate foreign visitors make clear the meaning of the logo. Chang'an will be translated into "Chang an Avenue", the people of East translated into "East Renmin Road" and it is consistent with international practice to facilitate understanding of foreign guests.

\section{The Problems Analysis of Using English in Urban area}

The use of English is in the convenience of foreigners living in China, while also providing opportunities and culture atmosphere to learn English for the Chinese people, improve the city's image. But while the English is widely used in Chinese cities, there have been some problems.

First, governments at all levels lack of English instructions and supervision for the construction of urban culture, there is no overall planning, resulting in English culture is uneven and confusing in the construction of various cities now. Even the same city, the construction of English culture is also a bit confusing. For example, in some cities, plenty of streets signs are both English and Chinese, some are Chinese characters and pinyin; the English translation of attractions is dispensable; in large-scale supermarkets, the mark in English and Chinese language is also inconsistent. In addition, there are many translation errors in tourist attractions and city logo and even in Beijing, Shanghai and other cities.

Second, urban culture construction lacks of integrating various English and coordinate resources utilization. There are no uniform requirements of primary and secondary schools to learn English cultural knowledge; university didn’t conduct system English cultural activities; a variety of media lack of guidance to introduce English culture; Community has no action in English cultural 
construction.

For the city's English culture construction current situation, some scholars did some research. Song Jie and Zhang Chengzhi study how the role of English in international cultural city construction in Baoding Case. Zheng Zhuqun, Guo Jianjing and Zhaoyu Zhang studied other English translation in public places. Zhu Yuqing discussed the English casual cultural patterns taking the example of the community in Langfang and created English leisure culture community features. These studies made a very good suggestion from different angles on the English culture of urban construction.

\section{Conclusion}

The various pragmatic failures in using English in cities are important problem in the process of construction of urban civilization which cannot be ignored. To avoid translation errors on public signs, first from the ideological emphasis, the introduction of appropriate management. Second, we must focus on field research and collecting relevant information public signs, but also invite experts to participate in all aspects of revision in order to ensure the accuracy and usefulness of the English translation. Only in this way, the level of internationalization of the city can improve all-round.

\section{References}

[1] Jia Xinzhang, Li Jingyuan. Chinese Translation, Vol. 6 (2014) No 53, p.25-26

[2] Wang Qunyong. Southwest Agricultural University, Vol. 12 (2015) No 27, p.74-76

[3] Qian Xiyuan, Jing Jianfen, Hou XuSiem. Chinese Translation, Vol. 30 (2014) No 19, p.144-145

[4] Wang Kuailiang. Liaoning University, Vol. 29 (2008) No 27, p.21-23

[5] Zhang Gongxu, Sun Jing. Chinese Translation, Vol. 8 (2013) No 27, p.57-60 